Pontifíia $U_{\text {niversidade }}$ Católica $_{\text {at }}$

Cristiane Silva Rocha Damasceno

\title{
Modelagem Geológica e Geomecânica 3D e Análises de Estabilidade 2D dos Taludes da Mina de Morro da Mina, Conselheiro Lafaiete, MG, Brasil
} DissertaçÃo de Mestrado

Departamento de EngenhaRIA CiVIL Programa de Pós-Graduação em Engenharia Civil 


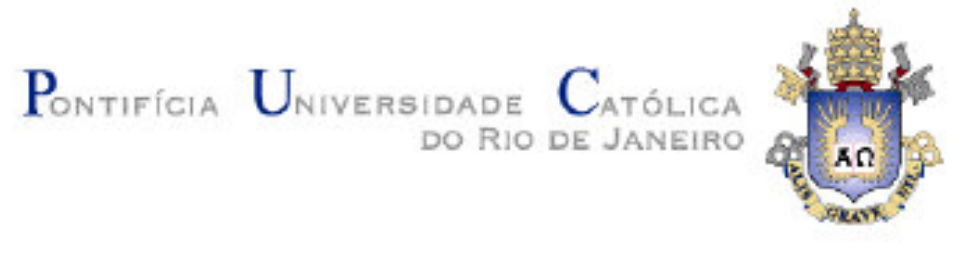

Cristiane Silva Rocha Damasceno

Modelagem Geológica e Geomecânica 3D e Análises de Estabilidade 2D dos Taludes da Mina de Morro da Mina, Conselheiro Lafaiete, MG, Brasil

Dissertação de Mestrado

Dissertação apresentada como requisito parcial para obtenção do título de Mestre pelo Programa de Pós-Graduação em Engenharia Civil da PUC-Rio.

Orientador: Sérgio Augusto Barreto da Fontoura 


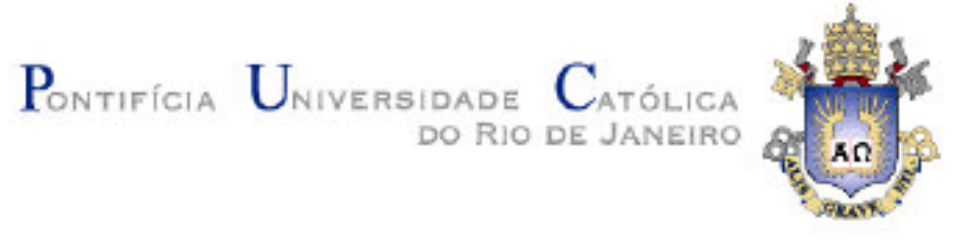

Cristiane Silva Rocha Damasceno

\begin{abstract}
Modelagem Geológica e Geomecânica 3D e Análises de Estabilidade 2D dos Taludes da Mina de Morro da Mina, Conselheiro Lafaiete, MG, Brasil
\end{abstract}

Dissertação apresentada como requisito parcial para obtenção do título de Mestre pelo Programa de PósGraduação em Engenharia Civil da PUC-Rio. Aprovada pela Comissão Examinadora abaixo assinada.

Prof. Sérgio Augusto Barreto da Fontoura

Orientador

Departamento de Engenharia Civil - PUC-Rio

Prof. Alberto de Sampaio Ferraz Jardim Sayão

Departamento de Engenharia Civil - PUC-Rio

Prof. Ana Cristina Castro Fontenla Sieira Departamento de Estruturas e Fundações - UERJ

Prof. José Eugênio Leal Coordenador Setorial do Centro Técnico Científico - PUC-Rio 
Todos os direitos reservados. É proibida a reprodução total ou parcial do trabalho sem autorização da universidade, da autora e do orientador.

\section{Cristiane Silva Rocha Damasceno}

Graduou-se em Engenharia Civil - ênfase em Estruturas, na UERJ (Universidade do Estado do Rio de Janeiro) em 2005/1. Presta serviço voluntário de caráter filantrópico, atuando como responsável técnica pela execução de furos de sondagens, para dimensionamento de estrutura e construção de Salões do Reino das Testemunhas de Jeová.

Ficha Catalográfica

Damasceno, Cristiane Silva Rocha

Modelagem Geológica e Geomecânica 3D e Análises de Estabilidade 2D dos Taludes da Mina de Morro da Mina, Conselheiro Lafaiete, MG, Brasil / Cristiane Silva Rocha Damasceno; orientador: Sérgio Augusto Barreto da Fontoura. - 2008.

165 f.: il.; $30 \mathrm{~cm}$

Dissertação (Mestrado em Engenharia Civil) - Pontifícia Universidade Católica do Rio de Janeiro, Rio de Janeiro, 2008.

Inclui bibliografia.

1. Engenharia civil - Teses. 2. Minas a céu aberto. 3. Modelagem. 4. Geoestatística. 5. Análises de estabilidade. I. Fontoura, Sérgio Augusto Barreto da. II. Pontifícia Universidade Católica do Rio de Janeiro. III. Departamento de Engenharia Civil. IV. Título. 
Ao meu Soberano Altíssimo Senhor Jeová, pois "Digno és, Jeová, sim, meu Deus, de receber a glória, e a honra, e o poder, porque criaste todas as coisas e porque elas existiram e foram criadas por tua vontade" (Revelação/Apocalipse 4:11). 


\section{Agradecimentos}

Ao meu amado Deus Jeová por ter permitido que eu chegasse até aqui em minha vida, por ter cuidado de mim, e ter me guiado por bons caminhos ao longo deste curso que concluo agora, e ao longo da minha vida, pois "desde o ventre de minha mãe tens sido meu Deus" (Sal 22:10).

Ainda ao meu Soberano Deus, pela ajuda recebida através dos meus queridos pais e irmãos na fé; através das inúmeras pessoas maravilhosas que conheci na Universidade da qual sou originária - UERJ, e na Universidade onde me encontro agora - PUC-Rio, sendo que nesta a lista vai desde o pessoal da "Van dos Funcionários da PUC" até o pessoal do GTEP, passando pelo pessoal e professores do Departamento de Engenharia Civil; e por meio das instituições CAPES, VALE, na pessoa de Paulo R. Franca, Schlumberger, Rocscience, e do próprio GTEP, na pessoa do meu estimado orientador Sérgio A. B. da Fontoura, que sem as quais este trabalho não poderia ter sido realizado, e principalmente, pelo privilégio de ter levado o nome Dele a pessoas que nunca ouviram falar sobre ele, pois conforme está escrito: "como ouvirão, se não houver quem pregue?" (Ro 10:14). 


\section{Resumo}

Damasceno, Cristiane Silva Rocha; Fontoura, Sérgio Augusto Barreto da. (Orientador) Modelagem Geológica e Geomecânica 3D e Análises de Estabilidade 2D dos Taludes da Mina de Morro da Mina, Conselheiro Lafaiete, MG, Brasil. Rio de Janeiro, 2008. 165 p. Dissertação de Mestrado - Departamento de Engenharia Civil, Pontifícia Universidade Católica do Rio de Janeiro.

O trabalho propõe uma metodologia para elaboração de modelos geológicos e geomecânicos (3D) e realização de análises de estabilidade (2D) de taludes rochosos de minas a céu aberto, com base nos dados da mina de Morro da Mina, fornecidos pela empresa VALE, a qual esta pertence. A metodologia está dividida em duas etapas: modelagem e análises de estabilidade. Para a modelagem, foi utilizado o software Petrel 2004, que oferece ferramentas geoestatísticas, possibilitando a extrapolação das informações geotécnicas pontuais c', $\phi$ ', RQD, Q e RMR, obtidas por meio de testemunhos de sondagem, para o maciço inteiro. Utilizou-se a técnica de Krigagem Ordinária. $\mathrm{O}$ modelo gerado representou bem a distribuição destas propriedades no espaço. $\mathrm{Na}$ etapa de análise de estabilidade, foram utilizadas seções resultantes da modelagem geomecânica. Dois tipos de análises foram realizados: análises cinemáticas, com utilização do software Dips, da Rocscience, e análises por equilíbrio limite dos taludes globais e das bancadas, utilizando-se o software Slide 5.0, também da Rocscience. No primeiro tipo, realizado com dois conjuntos de mapeamentos diferentes, foi constatado que as bancadas devem receber bastante atenção nesta mina, e no segundo tipo, foi verificada a segurança quanto à ruptura circular das bancadas e taludes globais, porém recentemente ocorreu uma ruptura em um dos locais analisados. Os programas RocData $4.0 \mathrm{e}$ RocProp, ambos da Rocscience, foram utilizados para estimar os parâmetros de resistência de Mohr-Coulomb, e os softwares AutoCAD 2004 e Microsoft Office Excel auxiliaram na preparação dos arquivos de entrada no Petrel 2004 e no Slide 5.0.

\section{Palavras-chave}

Minas a Céu Aberto; Modelagem; Geoestatística; Análises de Estabilidade. 


\section{Abstract}

Damasceno, Cristiane Silva Rocha; Fontoura, Sérgio Augusto Barreto da. (Advisor) Geological and Geomechanics Modelling 3D and Stability Analyses 2D of The Slopes of the Morro da Mina Mine, Conselheiro Lafaiete, MG, Brazil. Rio de Janeiro, 2008. 165 p. MSc. Thesis Department of Civil Engineering, Pontifícia Universidade Católica do Rio de Janeiro.

This work presents a methodology to develop geological and geomechanic models (3D) and to carry out stability analyses (2D) of rock slopes of open pit mine, based on data of Morro da Mina mine, provided by the mining company VALE. The methodology is divided in two stages: modelling and stability analyses. For the modelling, the software Petrel 2004, which allows the use of geostatistical tools, was used, being possible the spatial distribution of geotechnical information, obtained from borehole cores, for the whole rock mass. The technique of Ordinary Kriging was used. The modeled properties were the following: c', $\phi$ ', RQD, Q e RMR. The generated model represented well the spatial distribution of these properties. The stability analyses were carried out using $2 \mathrm{D}$ sections and the necessary rock mass parameters were obtained from the geomechanical model. Two types of analyses were carried out: kinematic analyses, with use of the software Dips, from Rocscience, and limit equilibrium analyses of the global slopes and the benches, where the software Slide 5.0, also from Rocscience was used. The Kinematic analyses, carried out considering two sets of joint orientations, suggested that the benches have to receive enough attention in this mine, and the limit equilibrium analyses for circular failure of the benches and global slopes indicated high factors of safety. However, before this work initiating a failure already had happened in one of the sections analyzed. The programs RocData 4.0 and RocProp, both from Rocscience, were used to estimate the Mohr-Coulomb strength parameters, and the programs AutoCAD 2004 and Microsoft Office Excel helped at the development of the input files in the Petrel 2004 and Slide 5.0.

\section{Keywords}

Open Pit Mines; Modelling; Geostatistics; Stability Analyses. 


\section{Sumário}

1 Introdução 20

1.1. Motivação 20

1.2. Objetivo 21

1.3. Escopo 22

2 Caracterização e Modelagem de Maciços Rochosos de Minas a Céu Aberto 24

2.1. Considerações sobre Minas a Céu Aberto 24

2.2. Condicionantes dos Taludes de Minas 25

2.2.1. A Geometria 25

2.2.2. A Geologia Local 27

2.2.3. A Água Subterrânea $\quad 29$

2.2.4. O Estado de Tensão nos Taludes 30

2.3. Caracterização Geomecânica de Taludes Rochosos 32

2.4. Propriedades de Resistência 34

2.4.1. Resistência das Rochas Intactas 34

2.4.2. Resistência das Descontinuidades $\quad 35$

2.4.3. Resistência de Maciços Rochosos 36

2.5. Sistemas de Classificação de Maciços Rochosos 42

2.6. Modelagem Geológica e Geomecânica de Maciços Rochosos 45

2.7. Estabilidade de Taludes 48

3 Caracterização Geotécnica da Mina de Morro da Mina 52

3.1. Mina de Morro da Mina 52

3.2. Geologia da Área $\quad 54$

3.2.1. Litotipos da Cava $\quad 58$

3.2.2. Feições Estruturais 60

3.2.2.1. Bandamento Composicional $S_{0} \quad 61$

$\begin{array}{ll}\text { 3.2.2.2. Xistosidade } S_{n} & 61\end{array}$

3.2.2.3. Clivagem de Crenulação $S_{n+1} \quad 62$

3.2.2.4. Foliação Milonítica $S_{m}$ em Zonas de Cisalhamento 63

3.2.2.5. Falhas/Fraturas 64

3.2.2.6. Eixos de Boudin $\delta_{\mathrm{n}} \quad 66$ 
3.2.2.7. Eixos de Dobras $\beta_{\mathrm{n}} \quad 66$

3.3. Modelagem Geomecânica e Hidrogeológica da Mina 67

3.3.1. Investigações Geotécnicas da Área da Cava 67

3.3.2. Setorização Geomecânica do Maciço da Cava 70

3.3.3. Parâmetros Geomecânicos 71

3.3.3.1. Caracterização $\quad 71$

$\begin{array}{ll}\text { 3.3.3.2. Resistência } & 74\end{array}$

$\begin{array}{ll}\text { 3.3.4. Ocorrência de Intemperismo } & 78\end{array}$

3.3.5. Investigações Hidrogeológicas da Área da Cava 79

3.3.5.1. Inventário dos Pontos D'Água 79

3.3.5.2. Análise Hidroquímica 80

3.3.5.3. Sistemas Aqüíferos $\quad 81$

3.3.6. Parâmetros Hidrodinâmicos 82

3.3.7. Modelo Geomecânico Existente 84

3.3.8. Modelo Hidrogeológico Existente 84

4 Modelagem Geológica e Geomecânica 3D da Mina Utilizando o Software Petrel $2004 \quad 86$

4.1. Metodologia 86

4.2. Considerações sobre o Software Petrel 86

4.3. Análise dos Dados Recebidos $\quad 88$

4.4. Material Utilizado na Modelagem $\quad 88$

4.5. Arquivos de Entrada $\quad 89$

4.6. Modelo Geométrico 3D da Mina 90

4.7. Upscaling dos Dados 92

4.8. Modelo Geológico 3D da Mina 93

4.8.1. Análise Crítica dos Resultados 98

4.9. Análise Geoestatística e Modelagem Geomecânica 3D da Mina 99

4.9.1. Análise Estatística 99

4.9.2. Análise Estrutural 102

4.9.3. Análise Crítica dos Resultados 108

4.9.4. Krigagem e Modelo Geomecânico 3D da Mina de Morro da Mina 109

4.9.5. Análise Crítica dos Resultados $\quad 115$

5 Análises de Estabilidade dos Taludes da Mina 117

5.1. Mecanismos Potenciais de Ruptura 117

$\begin{array}{ll}\text { 5.1.1. Estudo das Descontinuidades Preocupantes } & 117\end{array}$ 
5.1.2. Orientação dos Taludes em Relação às Descontinuidades 123

5.2. Análises de Estabilidade Cinemáticas 124

5.2.1. Análise Crítica dos Resultados $\quad 130$

5.3. Análises de Estabilidade por Equilíbrio Limite de Seções Típicas 131

5.3.1. Análise Crítica dos Resultados $\quad 141$

6 Conclusões e Sugestões 144

6.1. Conclusões 144

$\begin{array}{lr}\text { 6.2. Sugestões } & 147\end{array}$

$\begin{array}{lr}\text { Referências Bibliográficas } & 149\end{array}$

$\begin{array}{ll}\text { Anexos } & 157\end{array}$ 


\section{Lista de Figuras}

Figura 2.1 - Esquema de uma mina com seus elementos (Abrão \& Oliveira, 2004)

Figura 2.2 - Parâmetros que definem a geometria de uma mina a céu aberto 26 Figura 2.3 - Superfície de ruptura complexa, governada pelas descontinuidades menores e maiores, e as pontes de rocha (Hoek et al., 2000, modificada por Zea \& Celestino, 2004)

Figura 2.4 - Resistência à Compressão Uniaxial e Classes de Alteração (Vaz,

Figura 2.5 - Estimativa de GSI para maciços rochosos fraturados (Marinos et al., 2005)

Figura 2.6 - Estimativa de GSI para maciços rochosos heterogêneos (Flysch) (Marinos et al., 2005)

Figura 3.1 - Localização da Mina Morro da Mina e todo seu complexo (VALE, 2006)

Figura 3.2 - Produtos da mina (VALE, 2006). Figura a: LG13 - Minério de Manganês Carbonatado Granulado (entre 6,30mm e 75,00mm); Figura b: LF01 Minério de Manganês Carbonatado Fino (6,30mm)

Figura 3.3 - Cenário deposicional originador dos corpos de manganês

(Geoexplore, 2005)

Figura 3.4 - Contato tectônico do minério de manganês sílico-carbonatado com granitóide, envolvido por um dobramento isoclinal assimétrico, em zona de cisalhamento com biotita xisto carbonoso (Geoexplore, 2005)

Figura 3.5 - Diagrama estrutural de pólos de $S_{0}$ dos Setores da mina (Geoexplore, 2005)

Figura 3.6 - Diagrama estrutural de pólos de $S_{n}$ dos Setores da mina (Geoexplore, 2005)

Figura 3.7 - Exemplos de Clivagem de Crenulação. Figura a: clivagem de crenulação observada na zona de charneira de uma dobra maior (as dobras nos microlitons são simétricas); Figura b: clivagem de crenulação observada num flanco de uma dobra maior (as microdobras são assimétricas) 
Figura 3.8 - Zona de Cisalhamento em biotita-feldspato-quartzo xisto, com porfiroblastos estirados e sombras de pressão em sua cauda

(Geoexplore, 2005)

Figura 3.9 - Estilo de falhamento oblíquo em Zona de Cisalhamento, no biotita xisto grafitoso (Geoexplore, 2005)

Figura 3.10 - Diagramas estruturais de planos de falhas para os setores da mina (Geoexplore, 2005)

Figura 3.11 - Exemplo de slickenside. O bloco que assenta sobre a superfície observada deslocou-se da esquerda para a direita, relativamente ao bloco inferior. A seta indica o sentido do bloco de cima

Figura 3.12 - Exemplos de Boudin. À esquerda: exemplo geral de boudin. À direita: Formas de boudinage em biotita xisto grafitoso - Mina de Morro da Mina (Geoexplore, 2005)

Figura 3.13 - Em planta, dobramento isoclinal simétrico com eixos verticalizados (Geoexplore, 2005)

Figura 3.14 - Posição dos 39 furos de sondagem efetivamente usados, em relação à mina

Figura 3.15 - Setorizações da mina: Geoexplore (2005) - Setores I, II e III; SBC (2001) - Setores SW1, SW2, NW e NE

Figura 3.16 - Visualização dos taludes da cava com as direções cardeais e colaterais aproximadas (Vale, 2006)

Figura 3.17 - Visualização dos taludes da cava com as direções colaterais aproximadas (Vale, 2006) 79

Figura 3.18 - Visualização da posição das nascentes na cava da mina

Figura 4.1 - Geometria da Cava da mina de Morro da Mina

Figura 4.2 - Visualização das posições das bocas dos furos e suas trajetórias vista de cima da cava $\quad 91$

Figura 4.3 - Visualização espacial das trajetórias dos furos de sondagens 91 Figura 4.4 - Informações ao longo dos furos de sondagens - RQD 92 Figura 4.5 - Upscaling RQD 93

Figura 4.6 - Seqüência de furos de sondagem e Well Tops 94

Figura 4.7 - Horizons intermediários - vista do Sul 97

Figura 4.8 - Horizons intermediários - vista do Nordeste 98

Figura 4.9 - Transformação 1D Trend para a variável Q, Zona 3, representando o ajuste mais difícil desta transformação $-F C=0,148759100$ 
Figura 4.10 - Transformação 1D Trend para a variável RQD, Zona 1, representando o melhor ajuste desta transformação - FC $=0,70704$

Figura 4.11 - Transformação Normal Score para a variável Q, Zona 1, representando o ajuste mais difícil desta transformação $-\operatorname{Min}=-1,592$, $\operatorname{Max}=6,69, \sigma=0,99986$

Figura 4.12 - Transformação Normal Score para a variável RMR, Zona 1, representando o melhor ajuste desta transformação $-\operatorname{Min}=-3,262$,

$\operatorname{Max}=3,484, \sigma=0,99986$ 102

Figura 4.13 - Semivariograma representando um mau ajuste para a Major Direction, variável RQD, Zona $1-$ Sill $=0,785$

Figura 4.14 - Semivariograma representando um bom ajuste para a Major

Direction, variável C, Zona $1-$ Sill $=1$

Figura 4.15 - Semivariograma representando um mau ajuste para a Minor

Direction, variável RQD, Zona $3-$ Sill $=0,724$

Figura 4.16 - Semivariograma representando um bom ajuste para a Minor Direction, variável RMR, Zona $1-$ Sill $=1$

Figura 4.17 - Semivariograma representando um mau ajuste para a Vertical Direction, variável RQD, Zona 3 - Sill $=0,785$

Figura 4.18 - Semivariograma representando um bom ajuste para a Vertical Direction, variável PHI, Zona $3-$ Sill $=1$

Figura 4.19 - Modelo Geomecânico 3D da mina de Morro da Mina - RQD vista de cima da cava

Figura 4.20 - Demais vistas e cortes da mina - RQD

Figura 4.21 - Modelo Geomecânico 3D da mina de Morro da Mina - Q vista de cima da cava

Figura 4.22 - Demais vistas e cortes da mina $-Q$

Figura 4.23 - Modelo Geomecânico 3D da mina de Morro da Mina - RMR vista de cima da cava

Figura 4.24 - Demais vistas e cortes da mina - RMR

Figura 4.25 - Modelo Geomecânico 3D da mina de Morro da Mina - c' (MPa) vista de cima da cava

Figura 4.26 - Demais vistas e cortes da mina - c' (MPa)

Figura 4.27 - Modelo Geomecânico 3D da mina de Morro da Mina - $\phi^{\prime}\left({ }^{\circ}\right)-$ vista de cima da cava

Figura 4.28 - Demais vistas e cortes da mina - $\phi^{\prime}\left({ }^{\circ}\right)$ 
Figura 5.1 - Comparações entre os resultados dos mapeamentos de foliações da Geoexplore (2005) e SBC (2001)

Figura 5.2 - Comparações entre os resultados dos mapeamentos de falhas/fraturas da Geoexplore (2005) e SBC (2001)

Figura 5.3 - Comparação entre os estereogramas das atitudes das descontinuidades levantadas nos mapas da SBC (2001) e Geoexplore (2005) Setor SW1

Figura 5.4 - Comparação entre os estereogramas das atitudes das descontinuidades levantadas nos mapas da SBC (2001) e Geoexplore (2005) Setor SW2

Figura 5.5 - Comparação entre os estereogramas das atitudes das descontinuidades levantadas nos mapas da SBC (2001) e Geoexplore (2005) Setor NW

Figura 5.6 - Comparação entre os estereogramas das atitudes das descontinuidades levantadas nos mapas da SBC (2001) e Geoexplore (2005) Setor NE

Figura 5.7 - Resultados das análises cinemáticas - Ruptura Planar

Figura 5.8 - Resultados das análises cinemáticas - Ruptura Planar e Cunha 126 Figura 5.9 - Resultados das análises cinemáticas - Ruptura em Cunha 127 Figura 5.10 - Resultados das análises cinemáticas - Ruptura por Tombamento SW1, SW2 128

Figura 5.11 - Resultados das análises cinemáticas - Ruptura por Tombamento NW, NE

Figura 5.12 - Setores da cava com seus respectivos tipos de ruptura possíveis de ocorrer

Figura 5.13 - Representação da localização das seções escolhidas para as análises de estabilidade

Figura 5.14 - Utilização dos parâmetros de resistência obtidos do Petrel 2004 no programa Slide 5.0

Figura 5.15 - Idealização das camadas de material no programa Slide 5.0, a partir dos resultados obtidos do programa Petrel 2004, para a propriedade $\phi$ ' 136 Figura 5.16 - Correlação entre os valores de $\phi^{\prime}\left({ }^{\circ}\right)$ e $\gamma\left(\mathrm{MN} / \mathrm{m}^{3}\right)$ assumidos para as rochas da mina de Morro da Mina

Figura 5.17 - Esquema ilustrativo das etapas de definição de $\gamma$ para as camadas de material no programa Slide 5.0

Figura 5.18 - Resultados das análises de estabilidade para a Seção SW1 138

Figura 5.19 - Resultados das análises de estabilidade para a Seção SW2 139 
Figura 5.20 - Resultados das análises de estabilidade para a Seção NW

Figura 5.21 - Visualização dos resultados do Upscaling e da interpolação por Krigagem da propriedade c' 


\section{Lista de Tabelas}

Tabela 2.1 - Métodos de Análise de Estabilidade por Equilíbrio Limite (De

Campos, 1985)

Tabela 3.1 - Principais elementos estruturais presentes na mina 60

Tabela 3.2 - Resumo das sondagens rotativas 69

Tabela 3.3 - Setorização adotada em 2000 pela SBC (SBC, 2001) 70

Tabela 3.4 - Correlação entre os Graus de Resistência, Consistência, e Alteração (baseado em SBC (2004)) 73

Tabela 3.5 - Parâmetros de Resistência estimados por SBC (2001) 74

Tabela 3.6 - Correlações para adoção do valor de GSI 75

Tabela 3.7 - Parâmetros de Resistência para as principais litologias da Mina 76

Tabela 3.8 - Coordenadas, cotas e vazões das nascentes da cava da mina 80

Tabela 3.9 - Parâmetros físico-químicos das nascentes da cava da mina $\quad 80$

Tabela 3.10 - Parâmetros obtidos da interpretação do ensaio de bombeamento ( $\mathrm{T}$ - Transmissividade, $\mathrm{b}$ - espessura saturada do meio, $\mathrm{K}$ - Condutividade Hidráulica, S - Coeficiente de Armazenamento) (MDGEO, 2001) 83

Tabela 4.1 - Tabela resumo dos ajustes dos semivariogramas para a Zona 1106 Tabela 4.2 - Tabela resumo dos ajustes dos semivariogramas para a Zona 2107 Tabela 4.3 - Tabela resumo dos ajustes dos semivariogramas para a Zona 3107

Tabela 5.1 - Resultados esperados de acordo com a gênese das estruturas presentes na cava da mina de Morro da Mina

Tabela 5.2 - Dados para análise de estabilidade cinemática

Tabela 5.3 - Resumo dos resultados das análises cinemáticas

Tabela 5.4 - Resumo dos casos estudados 


\section{Lista de Símbolos}

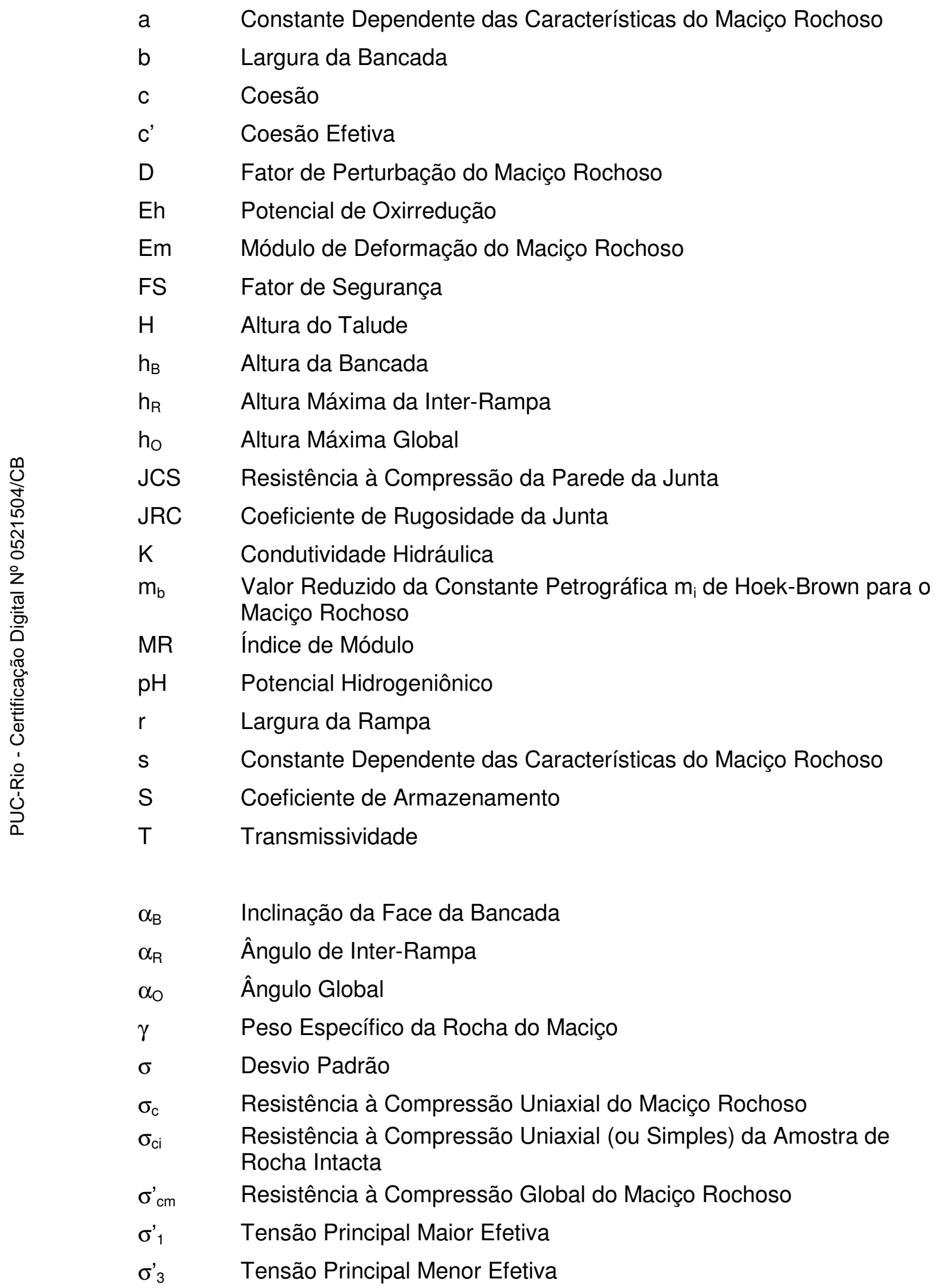




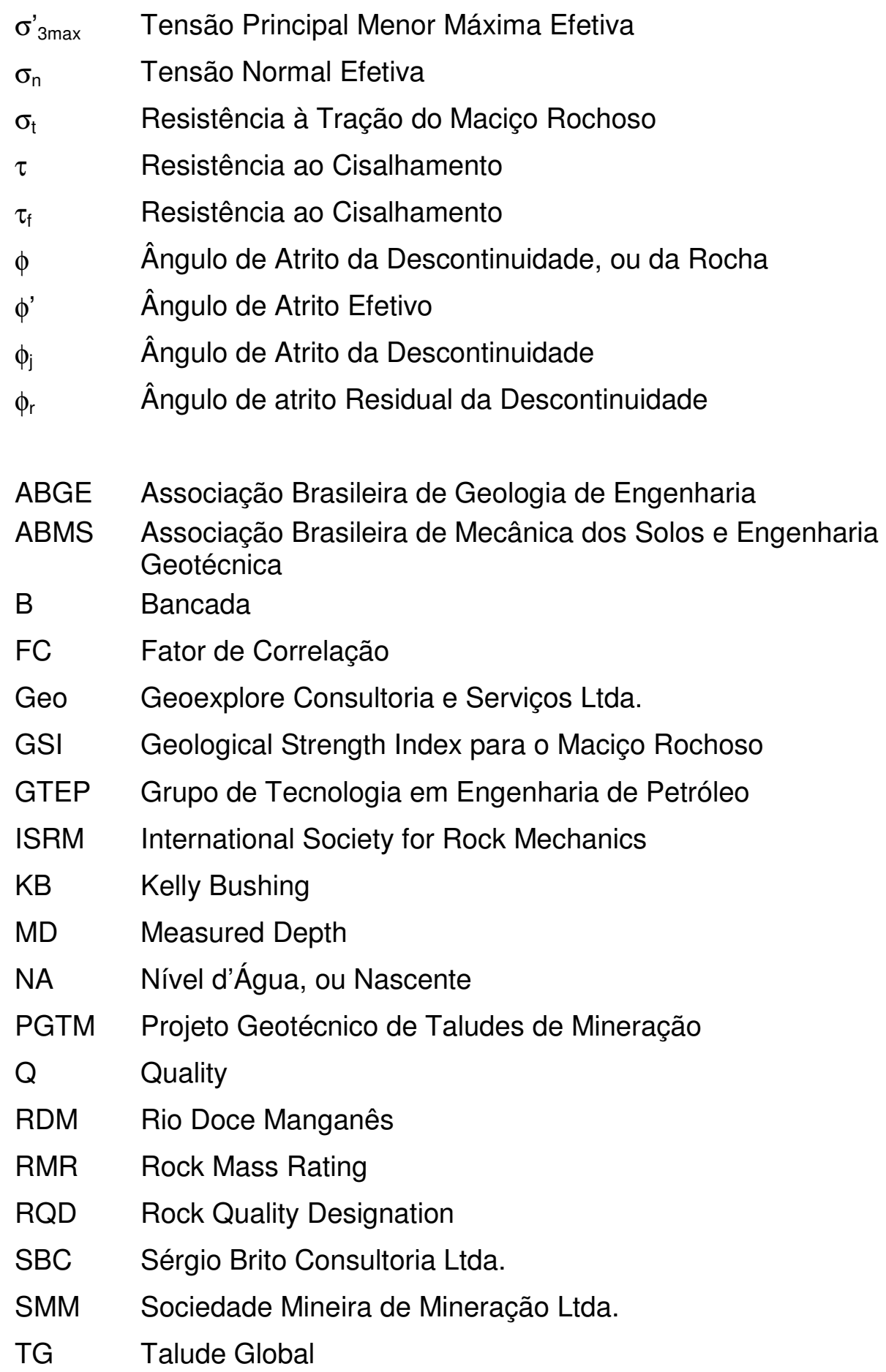


"Sabedoria é a coisa principal. Adquire sabedoria; e com tudo o que adquirires, adquire compreensão", "porque melhor é a sabedoria do que os corais, e mesmo todos os outros agrados não se podem igualar a ela" ( $\operatorname{Pr} 4: 7 ; 8: 11)$. 